\title{
Editorial on the Status of Hernia Surgery Back to Pure Tissue Repair or Forward to Tohubohu
}

\author{
Earl Byrnes Shouldice \\ Shouldice Hospital, Thornhill, Ontario, Canada \\ Email: ebshouldice@shouldice.com
}

Received 8 April 2014; revised 7 May 2014; accepted 6 June 2014

Copyright (C) 2014 by author and Scientific Research Publishing Inc. This work is licensed under the Creative Commons Attribution International License (CC BY). http://creativecommons.org/licenses/by/4.0/

(c) (i) Open Access

\begin{abstract}
Edoardo Bassini is considered the father of modern surgery. His early results revealed a $2.7 \%$ recurrence rate. Earl Shouldice, his true successor, has improved the results to less than $1 \%$. These results were produced by several well-known surgeons from 1970-2000 and well published. The need for mesh was meant for a small segment of the surgical patient population. What has happened? Generally, recurrence rates with mesh have not come down; instead, pain has become the bane of hernia repair as we begin the 21st century. A pain which makes the patient wish that he had a recurrence instead!
\end{abstract}

\section{Keywords}

Hernia, Hernia Editorial, Laparoscopy, Polypropylene Mesh, Pure Tissue Repairs

Tohubohu is an English word borrowed from the Hebrew. It describes the state of the Earth before Creation (Book I, Chapter I verse 2): chaos! Bassini in an infinitely more modest claim, established order out of anatomical chaos and a cure for an age-old, utterly confusing illness: inguinal hernia [1]. The miracle procedure took almost 1900 years of our common era to evolve (let us not go back to Creation whose date would be too heatedly argued)!

Edoardo Bassini performed his groundbreaking operation and catalogued the results on 262 patients, 11 of whom had a strangulated hernia, at a time when anaesthesia was rudimentary with Ether/Chloroform, antisepsis was tenuously gaining a foothold and antibiotics were still 60 years and two World Wars away! Four patients were lost to follow up, and one died of pneumonia on Day 15. Follow up to 4.5 years revealed a 2.7\% recurrence rate [2]! Such results made converts of William Halsted, Just Marie Lucas-Championniere and many contemporaries and gave rise to no less than eighty modifications. Despite minor changes to the original Bassini (stainless steel sutures, an additional suture line, continuous suture lines rather than interrupted ones, suspension of the 
distal cremasteric stump), my father E. E. Shouldice remained the most faithful disciple to this day in what has become known as the Bassini-Shouldice, the Canadian and the Shouldice repair!

The tradition of the Shouldice Hospital did not mean a stifling routine of a monotechnique in hernia surgery. The foundation of the hospital in 1945 [3] saw that the recurrence rate dropped from 19\% to less than $1 \%$. We fostered and encouraged the use of local anesthesia for obvious reasons, thus bringing safe surgery to an aging population for whom hernias can be an ugly reality attended by severe morbidity and mortality. We pioneered early ambulation whereby patients walk away from the operating table and consequently the elimination of pulmonary emboli which marred many a convalescence. More recently progress within our facilities saw the introduction of the first "gadget" in hernia surgery, the umbrella for femoral hernias, a gadget which turned out to be effective but too easily manufactured by a surgeon at the operating table [4]. The industry saw its potential and Bard created the Perfixplug which was not an improvement but in fact a dangerous imitation of the simpler umbrella. For inguino-femoral hernias, we introduced a "fletching", a 3-leaved "gadget" used in cases of total destruction of the inguinal ligament [5]. The fletching was withdrawn though quite successful in seven cases simply because it turned out to be a complex, time consuming operation when a simple wide sheet of prosthetic material was in fact quite adequate. From our hospital came also two new syndromes: dysejaculation and parapubic hernias. Dysejaculation, a rare complication in pure tissue repairs [6] is becoming the bane of hernia surgery and has become common place since the ever expanding and injudicious use of polypropylene mesh. The use of mesh applied laparoscopically presents a new problem since contact of a denuded, unprotected vas in the pelvis tends to coalesce with mesh, then invades it creating a new source of dysejaculation which is being reported more frequently [7]; parapubic hernias follow prostate surgery where access to prostate cancer necessitates resection of parts of the pubic bone resulting in hernias which repeatedly recurred until the bony defect in the pubic ramus is recognized and corrected [8].

The introduction of the composite bi-layered mesh (goretex-marlex) was also first designed and used at the Shouldice Hospital for intraperitoneal placement in difficult abdominal wall reconstructions [9]. It went on to become the Composix ${ }^{\circledR}$ as industry renamed it at our expense!

In anatomy we described a hitherto unknown venous circle in the space of Bogros [10]. We so appreciated the contributions of Bogros [11] and Fruchaud [12] that we made the effort to translate these original works which were already forgotten, from French to English. Their reception has been gratifying.

The introduction of laparoscopic surgery in the 1990s presented a new challenge which we did not ignore. The technique was not an easy one to acquire but once it was, after a long learning curve fraught with failures, it was still attended by what we felt would be eventual difficulties. Besides an expensive set up, a need for general anesthesia, uncommon but serious complications, access to care would become too restricted for the ever aging population and the patients with serious medical issues. The insertion of meshes in the spaces of Retzius, Bogros in contact with urinary bladder, femoral and iliac vessels, femoral nerves, lateral cutaneous nerves of the thigh and even obturator nerves seemed too daring and too risky when we already had a benign and effective operation. Though sound at first in principle, the laparoscopic technique still has not received universal and unequivocal approval for groin hernias. A sixth sense made us reject laparoscopic surgery for groin hernias much like the famed Rotschild group of London, England had refused to insure the Titanic! It just did not seem right! Except in Germany and Switzerland where use of laparoscopy reaches $26.9 \%$, after 25 years of presence, it is seldom seen above $7 \%$ to $25 \%$ in North America [13]. We have found in our unparalleled experience in the last 30 years which is based on 7500 operations a year, that if a mesh is needed, and it may be so in $2 \%$ - $4 \%$ of cases, a simple open anterior repair yields excellent results and with little fear for complications which could not be handled by an average surgeon. This was seen and confirmed in the now classic metanalysis by Neumayer et al. published in the N.E.J.M. [14] and which remains the classic reference publication.

Our continuing efforts are presently addressing the pain problem. Pain has overtaken recurrence as a complication with incidences ranging from $28.7 \%$ - 75.5\% [15] [16] and 12\% - 30\% [17]. Much is being written but little is being said. What physiology is being disturbed? What pathology is taking place? What mechanisms are being studied which account for inguinodynia? Our research, in cooperation with the University of Toronto is making some startling discoveries which are presently being submitted for publication in this issue of IJCM. Such research has not been funded by industry and is being done at arm's length and is, without doubt, going to influence our thinking. Already we are seeing that patients with laparoscopically inserted meshes who are suffering with severe pain are being rejected for the surgery of mesh removal. Rare is the surgeon willing to attempt this feat for fear of vascular and bladder complications. The Meshoma Foundation, a non-profit organiza- 
tion of Fort Lauderdale, Florida has collected a thousand cases of such patients who are scouring the world for surgeons willing to remove their laparoscopically inserted mesh. There are good reasons for apprehension.

A novel approach, which is actually a re-introduction of an older attitude and wisdom, is the wait and see attitude. It would seem that unless a hernia is accompanied by marked discomfort or size, or risk of strangulation, it may be a valid option to live with it rather than run the risk of post operative inguinodynia... "Let the patient be" [18]. A sad retrograde attitude in view of the fact that pure tissue repairs under local anesthesia, even if mesh were necessary, have become eminently feasible and safe procedures with minimal risks, if any.

Ironically, the only recommendation for a pure tissue repair in the EHS Guidelines is the presence of infection [19]. But who will know how to do one? From hearsay? From a manual? From historical texts? From Youtube? Perhaps we ought to etch it in stone for surely, we will have need for such a technique at some time. Did we not lose the art of making a Stradivarius, Guarnerius, Amati? Did we not lose the art of making the blue colored stained glass of the Chartres Cathedral? How were the pyramids built? Lost worthwhile technologies affect us all.

Most unexpectedly help is coming from the urologists and gynecologists who have been removing polypropylene meshes used in bladder and uterine suspensions. Erosions through the vaginal walls, bladders, urethras have led to fistulas, bleeding, pain, dyspareunia, recurrent infections leading to record breaking court settlements (11.2 and 5 million dollars) and class actions in the US and Canada. The filing of a complaint with the mesh manufacturing companies and the FDA are turning out to be insurmountable obstacles where patients have to be at death's door before anyone listens and registers a complaint or complication! The requirement by companies that patients provide an explant for analysis is a delaying tactic (meshes are never "defective") and a maneuver whereby a manufacturer may wash his hands of the problem ascribing the latter to either the surgeon or the patient's "rare and unusual reactions"!

Certainly the landscape is changing. Practices are changing. Informed consent is becoming topical, essential and properly obligatory. Of greatest concern too is the fact that pure tissue repairs are rare if no longer included in programs of the major hernia societies which have essentially become endoscopic surgical societies. The appearance of the "collaborative surgeon", who is retained and paid by the industry, is a delicate ethical issue which must be addressed by surgical societies and governing bodies. The problems of "conflict of interest" have never been greater. More than ever publications originate with the manufacturers and these submissions are becoming more difficult to detect or distinguish by the novice and neophytes. The policing of our practices by our own regulatory medical bodies is becoming an impossible task. What we fail to address will be taken up by the courts to the delight of the legal profession. Who decides on the evolution in medicine and surgery? The ethical physician, surgeon or industry? Whose interests are primordial here, the patients' or the investors'? The industry must serve the surgeon and not the surgeon the industry. The threat of a return to tohubohu has never been so real, so palpable!

\section{References}

[1] Bassini, E. (1887) Sulla cura radicale dell'ernia inguinale. Arch Soc Ital Chir, 4, 380.

[2] Bassini, E. (1889) Nuovo metodo operativo per la cura dell'erniainguinale. Prosperini, Padova.

[3] Bendavid, R. and Shouldice, E.E. (1995) A Biography. Problems in General Surgery, 12, 1-5.

[4] Bendavid, R. (1987) A Femoral Umbrella for Femoral Hernia Repair. Surgery, Gynecology Obstetrics, 65, $153-156$.

[5] Bendavid, R. (1986) The "Fletching”: A New Implant for the Treatment of Inguino-Femoral Hernias. International Surgery, 71, 248-251.

[6] Bendavid, R. (1992) "Dysejaculation”: An Unusual Complication of Inguinal Herniorrhaphy. Postgrad. Gen Surg, 4, 139-141.

[7] Bischoff, J.M., Linderoth, G., Aaswang, E.K, Werner, M.U. and Kehlet, H. (2012) Dysejaculation after Laparoscopic Inguinal Herniorrhaphy. Surgical Endoscopy, 26, 979-983. http://dx.doi.org/10.1007/s00464-011-1980-y

[8] Bendavid, R. (1990) Incisional Parapubic Hernias. Surgery, 108, 898-901.

[9] Bendavid, R. (1997) Composite Mesh(polypropylene-e-PTFE) in the Intrapritoneal Position. A Report of 30 Cases. Hernia, 1, 5-8. http://dx.doi.org/10.1007/BF02426380

[10] Bendavid, R. (1992) The Space of Bogros and the Deep Inguinal Venous Circulation. Surgery, Gynecology Obstetrics, 174, 355-358.

[11] Bogros, J.A. (1823) Essais surl'anatomie chirurgicale de la region iliaque. Thèse Méd, Paris, No. 153, 29 Août. 
[12] Fruchaud, H. (1956) Anatomie Chirurgicale des Hernies de l’Aine. Doin, Paris.

[13] Holtzheimer, R.G. (2009) Inguinal Hernia Repair: What to Do with the Evidence. World Journal of Surgery, 3, 20562057. http://dx.doi.org/10.1007/s00268-009-0176-2

[14] Meumayer, L., Giobbie-Hurder, A., Jonasson, O. and Fittzgibbons Jr., R. (2004) Open Mesh versus Laparoscopic Mesh Repair of Inguinal Hernia. NEJM, 350, 1819-1827. http://dx.doi.org/10.1056/NEJMoa040093

[15] Sondena, K., Nesvik, I., Breivik, K. and Korner, H. (2001) Long Term Follow-Up of 1059 Consecutive Primary and Recurrent Inguinal Hernias in a Teaching Hospital. European Journal of Surgery, 167, 125-129. http://dx.doi.org/10.1080/110241501750070583

[16] Nienhuijs, S.W., Boelens, O. and Strobbe, L.J.A. (2005) Pain after Anterior Mesh Repair. Journal of the American College of Surgeons, 200, 885-889. http://dx.doi.org/10.1016/j.jamcollsurg.2005.02.005

[17] Wright, R.C. and Sanders, E. (2011) Inguinal Neuritis Is Common in Primary Inguinal Hernia. Hernia, 15, 393-398. http://dx.doi.org/10.1007/s10029-011-0807-z

[18] Fitzgibbons Jr., R. (2012) Let the Patient Be. American Hernia Society Meeting.

[19] Simons, M.P., Aufenacker, T., Bay-Nielsen, M., et al. (2009) European Hernia Society Guidelines on the Treatment of Inguinal Hernia in Adult Patients. Hernia, 13, 343-403. http://dx.doi.org/10.1007/s10029-009-0529-7 
Scientific Research Publishing (SCIRP) is one of the largest Open Access journal publishers. It is currently publishing more than 200 open access, online, peer-reviewed journals covering a wide range of academic disciplines. SCIRP serves the worldwide academic communities and contributes to the progress and application of science with its publication.

Other selected journals from SCIRP are listed as below. Submit your manuscript to us via either submit@scirp.org or Online Submission Portal.
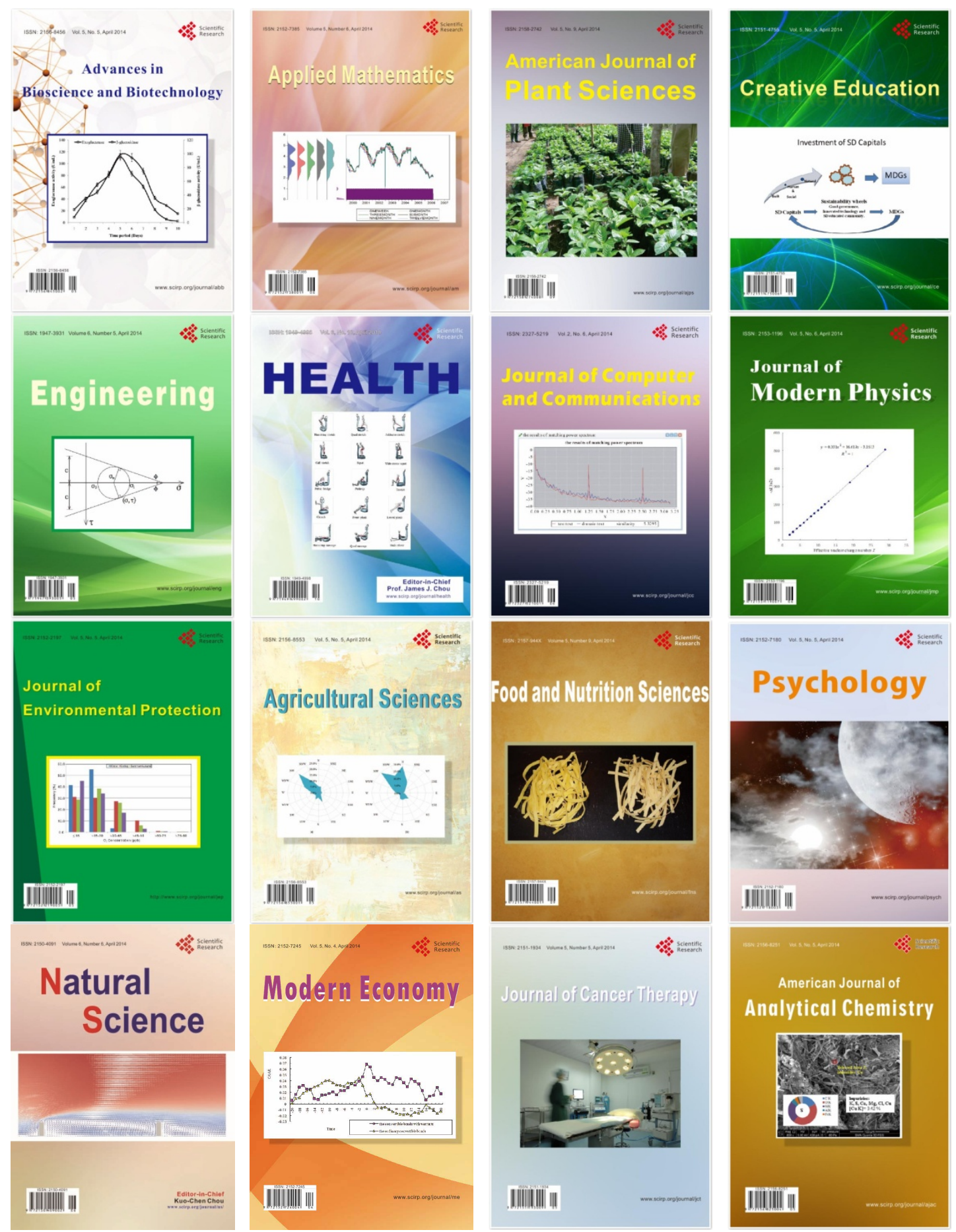